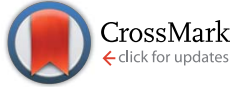

Cite this: RSC Adv., 2015, 5, 66636

\section{Visible light driven photocatalytic elimination of organic- and microbial pollution by rutile-phase titanium dioxides: new insights on the dynamic relationship between morpho-structural parameters and photocatalytic performance}

\author{
G. Veréb, ${ }^{\star a b}$ T. Gyulavári, ${ }^{a}$ Zs. Pap, ${ }^{\text {acd }}$ L. Baia, ${ }^{\text {de }}$ K. Mogyorósi, ${ }^{a}$ A. Dombi \\ and K. Hernádi ${ }^{\text {af }}$
}

\begin{abstract}
The characteristic properties and the resulted photocatalytic efficiencies of rutile-phase titanium dioxides were investigated in the present study. A series of rutile with different primary particle sizes $(5.2-290 \mathrm{~nm})$ were produced by a sol-gel method followed by calcination and were characterized by XRD, DRS, TEM, $X P S, E P R, I R$ and $\mathrm{N}_{2}$ adsorption. Their photocatalytic efficiencies were determined in the decomposition of phenol, and in the inactivation of $E$. coli bacteria under visible light irradiation. The results were compared with the photocatalytic performance of commercial Aldrich rutile and Aeroxide P25 powders. Of the noncommercial products, the $\mathrm{TiO}_{2}$ with the smallest particle size displayed the highest efficiency, while the surface-normalized photocatalytic performance was significantly higher for the larger rutile particles. This can be explained by the red shift of light absorption at higher calcination temperatures. Although Aldrich rutile and the corresponding laboratory-made photocatalyst exhibited similar structural features (e.g. particle size, specific surface area, morphology and light absorption), the latter proved to be less efficient despite its $\mathrm{Ti}^{3+}$ content (while Aldrich rutile contains only $\mathrm{Ti}^{4+}$ ). The main reason for the much higher photocatalytic performance was the presence of $\mathrm{Ti}-\mathrm{O}-\mathrm{O}-$ entities on the surface of Aldrich rutile. On the basis of these results, in the case of rutile-phase titanium dioxide, the presence of $\mathrm{Ti}-\mathrm{O}-\mathrm{O}-$ entities was more beneficial, than the presence of $\mathrm{Ti}^{3+}$ and low-binding-energy oxygen (which indicates defects) in relation with the photocatalytic performance under visible light irradiation.
\end{abstract}

Received 2nd March 2015 Accepted 29th July 2015

DOI: $10.1039 / \mathrm{c} 5 \mathrm{ra03719k}$

www.rsc.org/advances often as the most active phase,$^{6-8}$ and therefore it is the most widely investigated one, although it can be excited only by UV photons (the band gap for anatase is $3.2 \mathrm{eV}(\sim 387 \mathrm{~nm})$ for rutile is $\left.3.02 \mathrm{eV}(\sim 410 \mathrm{~nm})^{9}\right)$. On the other hand, rutile is more stable, ${ }^{6,10}$ can be efficient in visible light induced photocatalytic processes ${ }^{6,10-12}$ because of the lower band gap and can be more efficient than anatase in photocatalytic disinfection processes as described by Caratto et al. ${ }^{13}$ In our previous publication ${ }^{14}$ Aldrich rutile also showed much higher disinfection performance (under visible light irradiation) than commercial, anatase-phase, doped titanium dioxide (Kronos VLP7000), which has significantly higher performance in photocatalytic decomposition of phenol. The high disinfection performance of rutile grows the potential of utilization of this phase for indoor air- and surface cleaning processes. However, the sizedependence and desired surface specificities has not been investigated in detail in the literature.

Aldrich rutile demonstrated the mentioned high disinfection property ${ }^{14}$ despite its large average primer particle size $(\sim 315$ $\mathrm{nm})$ and very low $\left(3 \mathrm{~m}^{2} \mathrm{~g}^{-1}\right)$ specific surface area. Generally high specific surface area is preferred in photocatalytic processes, 
but Amano and Nakata ${ }^{15}$ described an improved photocatalytic activity for large rutile particles, which was explained by the increased lifetime of the photogenerated charge carriers. Large particle size can also be beneficial in disinfection processes, although no clear experimental evidences can be found in the literature.

The main aim of the present study was to investigate the liaison between the specific surface area (and/or surface properties) and the photocatalytic performances of rutile. Therefore, in the first instance nanosized $(\sim 5 \mathrm{~nm})$ non-doped rutile was obtained, followed by calcination at different temperatures (400-1000 ${ }^{\circ} \mathrm{C}$ ), resulting a series of rutile photocatalysts with finely tuned specific surface areas $\left(1-197 \mathrm{~m}^{2} \mathrm{~g}^{-1}\right)$. The photocatalytic performance was determined under visible light irradiation using phenol and $E$. coli bacteria as model contaminants. The investigated photocatalysts were characterized by XRD, DRS, TEM, XPS, EPR, IR and $\mathrm{N}_{2}$ adsorption.

\section{Experimental}

\subsection{Materials}

For the synthesis of different rutile photocatalysts, $\operatorname{Ti}(\mathrm{O}-n \mathrm{Bu})_{4}$ (Sigma-Aldrich, reagent grade, 97\%), HCl (Sigma-Aldrich; 37\%) and ultrapure water (Millipore Milli-Q) were used.

For the determination of the photocatalytic efficiencies, phenol (Spektrum 3D; analytical grade) and E. coli K12 bacteria were applied as model water contaminants. Photocatalytic experiments were carried out in $\mathrm{NaCl}$ (Spektrum 3D; analytical grade) solutions.

The reference $\mathrm{TiO}_{2}$ photocatalysts were commercially available Aeroxide P25 (produced by Evonik Industries) and Aldrich rutile.

\subsection{Methods and instrumentation}

2.2.1. Structural characterization of the $\mathrm{TiO}_{2}$-s. A Rigaku diffractometer was applied for X-ray diffraction (XRD) measurements $\left(\lambda_{\mathrm{Cu} \mathrm{K} \alpha}=0.15406 \mathrm{~nm}, 30 \mathrm{kV}\right.$, and $15 \mathrm{~mA}$, in the $20-40^{\circ}(2 \theta)$ regime). The average diameters of the particles were derived by using the Scherrer equation. The weight fractions of anatase and rutile were calculated from the peak areas of the anatase and rutile peaks at $25.3^{\circ}(2 \theta)$ and $27.5^{\circ}(2 \theta)$, respectively.

The DR spectra of the samples $(\lambda=220-800 \mathrm{~nm})$ were measured on a Jasco-V650 diode array computer-controlled (SpectraManager Software) spectrophotometer equipped with an integration sphere (ILV-724).

TEM micrographs were recorded on a Philips CM 10 instrument operating at $100 \mathrm{kV}$, using Formvar-coated copper grids.

The specific surface areas of the catalysts were determined by $\mathrm{N}_{2}$ adsorption at $77 \mathrm{~K}$, using a Micromeritics gas adsorption analyzer (Gemini Type 2375). The specific surface area was calculated via the BET method.

XPS measurements were performed on a Specs Phoibos 150 MCD instrument, with monochromatized $\mathrm{Al} \mathrm{K}_{\alpha}$ radiation $(1486.69 \mathrm{eV})$ at $14 \mathrm{kV}$ and $20 \mathrm{~mA}$, and a pressure lower than $10^{-9}$ mbar. Samples were mounted on the sample holder with the use of double-sided adhesive carbon tape. High-resolution Ti 2p and $\mathrm{O} 1 \mathrm{~s}$ spectra were recorded in steps of $0.05 \mathrm{eV}$ for the analyzed samples. The data obtained were analyzed with CasaXPS software. All peaks were deconvoluted by using the Shirley background and Lorentzian-Gaussian line shapes. The value of the Gaussian-Lorentzian ratio applied was 30 .

The FT-IR measurements were made with a Bruker Equinox 55 spectrometer with an integrated FRA 106 Raman module. Samples were ground with $\mathrm{KBr}$ and pressed into thin pellets (thickness $\approx 0.3 \mathrm{~mm}$ ). IR spectra were recorded with a spectral resolution of $2 \mathrm{~cm}^{-1}$.

EPR measurements were performed on powder samples using an EPR spectrometer ADANI PS 8400 system (ADANI Company, Minsk, Republic of Belarus) in the X-band. The samples were introduced in quartz tubes of $2 \mathrm{~mm}$ inner diameter. The EPR measurements were performed for all samples with the same conditions and using the same amount of powder.

2.2.2. Determination of photocatalytic efficiencies. The photocatalytic decomposition of phenol was carried out in a special photoreactor which was an open double-walled glass vessel, surrounded by a thermostating jacket at $25.0^{\circ} \mathrm{C}$. Around the vessel 4 conventional energy-saving compact fluorescence lamps (24 W; Düwi 25920/R7S lamps) were mounted. ${ }^{14}$ The spectrum of the light emitted by the lamps was slightly modified by circulating $1 \mathrm{M} \mathrm{NaNO}_{2}$ (Molar Chemicals, min. 99.13\%) aqueous solution in the thermostating jacket. This cut-off solution absorbed UV photons below $400 \mathrm{~nm}$, providing solely visible light irradiation for the $\mathrm{TiO}_{2}$-s (Fig. 1).

The $\mathrm{TiO}_{2}$ suspensions $\left(V=100 \mathrm{~mL} ; c_{\mathrm{TiO}_{2}}=1.0 \mathrm{~g} \mathrm{~L}^{-1}\right)$ which contained $0.1 \mathrm{mM}$ phenol as model contaminant were sonicated for $5 \mathrm{~min}$ before the photocatalytic tests and then stirred with a magnetic stirrer, and air was purged through the reaction mixture $(\mathrm{pH} \sim 6)$ during the experiments. Changes in phenol concentration were followed with an Agilent 1100 series HPLC system equipped with a Lichrospher RP 18 column, a

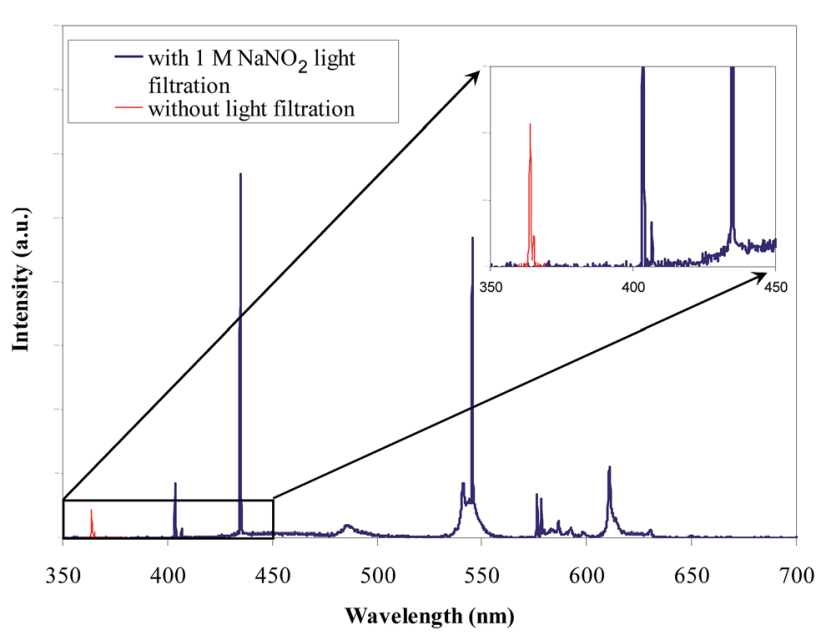

Fig. 1 Emission spectra of the conventional energy-saving compact fluorescence lamps (with and without $\mathrm{NaNO}_{2}$ cut-off filtration). 
methanol : water $=35: 65$ mixture being applied as eluent (detection was carried out at $210 \mathrm{~nm}$ ). The initial degradation rates were calculated from the slopes of the decay curves $(t=0) \cdot{ }^{16}$

Disinfection efficiencies were investigated in the same photoreactor as that in which the phenol decomposition experiments were carried out. The photocatalysts were added to a $0.9 \% \mathrm{NaCl}$ solution and homogenized by ultrasonication, and an $E$. coli $\mathrm{K} 12$ bacteria suspension was then inoculated into it; this suspension was prepared as follows. The bacterial culture was grown at $37{ }^{\circ} \mathrm{C}$ in $0.9 \% \mathrm{NaCl}$ solution containing $1 \%$ Tripton (Reanal, analytical grade) and $0.5 \%$ yeast extract (Scharlau, analytical grade) as nutrients. The culture was incubated for $24 \mathrm{~h}$ and then purified twice with a $0.9 \%$ saline solution by centrifugation ( $4000 \mathrm{rpm}, 2 \mathrm{~min}$ ) to eliminate the nutrients; the sediment was re-suspended in $0.9 \% \mathrm{NaCl}$ solution. The initial colony forming unit level in the investigated solution $(\mathrm{pH} \sim 7)$ was set to be $10^{4} \mathrm{CFU}$ per mL. During the photocatalytic disinfection experiments, samples were plated on agar gels (Merck, analytical grade) and the grown colonies were counted after a $24 \mathrm{~h}$ incubation at $37^{\circ} \mathrm{C}$ in the dark.

\section{Results and discussion}

\subsection{Synthesis of rutile $\mathrm{TiO}_{2}-\mathrm{S}$}

Nanosized rutile was produced by the hydrolysis of $\mathrm{Ti}(\mathrm{O}-n \mathrm{Bu})_{4}$ under highly acidic conditions. The synthesis method is very sensitive to the $\mathrm{H}^{+}$concentration as it is described by Tang et $a l .{ }^{17}$ They concluded that the optimal interval is about $\mathrm{Ti}(\mathrm{O}$ $n \mathrm{Bu})_{4}: \mathrm{H}^{+}: \mathrm{H}_{2} \mathrm{O} \sim 1: 2-3: 50$. Higher or lower acid concentrations can result in the crystallization of anatase (at nearly neutral $\mathrm{pH}$, amorphous $\mathrm{TiO}_{2}$ is formed by the hydrolysis of $\mathrm{Ti}(\mathrm{O}$ $\left.n \mathrm{Bu})_{4}\right) .{ }^{17}$ In our synthesis, the $\mathrm{Ti}(\mathrm{O}-n \mathrm{Bu})_{4}: \mathrm{H}^{+}: \mathrm{H}_{2} \mathrm{O}$ ratio of $1: 2: 50$ resulted in a mixture of anatase and rutile. At a ratio of $1: 3: 50$, the $\mathrm{TiO}_{2}$ produced was pure rutile. Tang et al. applied nitric acid to ensure the necessary $\mathrm{H}^{+}$concentration, but in the present study hydrochloric acid was applied to avoid $\mathrm{N}$ doping of the $\mathrm{TiO}_{2}$, because it induces interpretation errors of the obtained results, due to the additional visible light activity. ${ }^{\mathbf{1 8 - 2 3}}$ 15.7 mL hydrochloric acid was added in 44.6 mL Milli-Q water, and $21.3 \mathrm{~mL} \mathrm{Ti}(\mathrm{O}-n \mathrm{Bu})_{4}$ was then added to the solution dropwise $\left(1 \mathrm{~mL} \mathrm{~min}{ }^{-1}\right)$. The solution was aged for 15 min under magnetic stirring. After the termination of homogenization, two clear layers appeared, an upper (yellowish) organic phase and a lower colorless sol, which was isolated in a separating funnel. The sol was aged for $24 \mathrm{~h}$ in a water bath at $40{ }^{\circ} \mathrm{C}$. The temperature of the solution in this step is a critical condition in the synthesis. Higher temperatures result in faster crystallization, but the formation of anatase is to be expected above 60 ${ }^{\circ} \mathrm{C}$. ${ }^{24}$ The higher thermodynamic stability of rutile leads to a lower activation energy, which results in the preferred formation of rutile at lower temperatures. During the $24 \mathrm{~h}$ thermal treatment (in a water bath at $40{ }^{\circ} \mathrm{C}$ ), a white precipitate appeared in the sol, which indicated the crystallization of $\mathrm{TiO}_{2}$. The suspension was dried at $40{ }^{\circ} \mathrm{C}$ in a drying oven, and then ground in an agate mortar. The sample was washed by centrifugation 4 times in Milli-Q water. After the purification of this
$\mathrm{TiO}_{2}$ (designated Rutile-O), it was dried at $40{ }^{\circ} \mathrm{C}$, and again ground in an agate mortar.

\subsection{Preparation of the series of rutile samples with different particle sizes}

Rutile-O was calcined (Thermolyne 21100 tube furnace) at increasing temperatures to produce rutile samples with increasing particle sizes. Since the presence of $O$ vacancies and $\mathrm{Ti}^{3+}$ on the surface of $\mathrm{TiO}_{2}$ nanoparticles is generally beneficial for high photocatalytic performance, ${ }^{\mathbf{1 1 , 1 2 , 2 5 , 2 6}}$ a special calcination method (named as "RHSE - rapid heating, short exposure") was applied (Fig. 2) in the present study ${ }^{27,28}$ which results the appearance of these species. The temperatures applied were 400, 600, 700, 800, 900 and $1000{ }^{\circ} \mathrm{C}$, producing $\mathrm{TiO}_{2}$ samples designated Rutile-RHSE-400-1000. After the calcination, the samples were again ground in an agate mortar.

\subsection{Characterization of the photocatalysts}

Each of the photocatalysts were characterized by X-ray diffraction (XRD) measurements (Fig. 3 shows typical diffraction data of titanium dioxides).

The main crystalline phase of the prepared $\mathrm{TiO}_{2}$-S was rutile ( $>99 \mathrm{wt} \%$ ). The average diameters of the particles, estimated by using the Scherrer equation (when it is lower than $100 \mathrm{~nm}$ ), are presented in Table 1. Rutile-O contained very small nanoparticles $(D \sim 5 \mathrm{~nm})$ and, as expected, the average particle size increased (13-290 $\mathrm{nm}$ ) with the rising calcination temperature (400-1000 ${ }^{\circ} \mathrm{C}$ ). The primary particle sizes and phase distributions of commercial reference photocatalysts are also presented in Table 1. Aeroxide P25 contains $90 \mathrm{wt} \%$ anatase and $10 \mathrm{wt} \%$ rutile $\left(D_{\text {anatase }}=25.4 \mathrm{~nm}\right.$ and $\left.D_{\text {rutile }}=40 \mathrm{~nm}\right)$, while Aldrich rutile contains mainly (96 $\mathrm{wt} \%)$ rutile $(D \sim 315 \mathrm{~nm})$.

Transmission electron microscopic (TEM) images (Fig. 4.) were taken to determine the particle size (when it is higher than $100 \mathrm{~nm}$ ), the size distribution and the morphology of the particles.

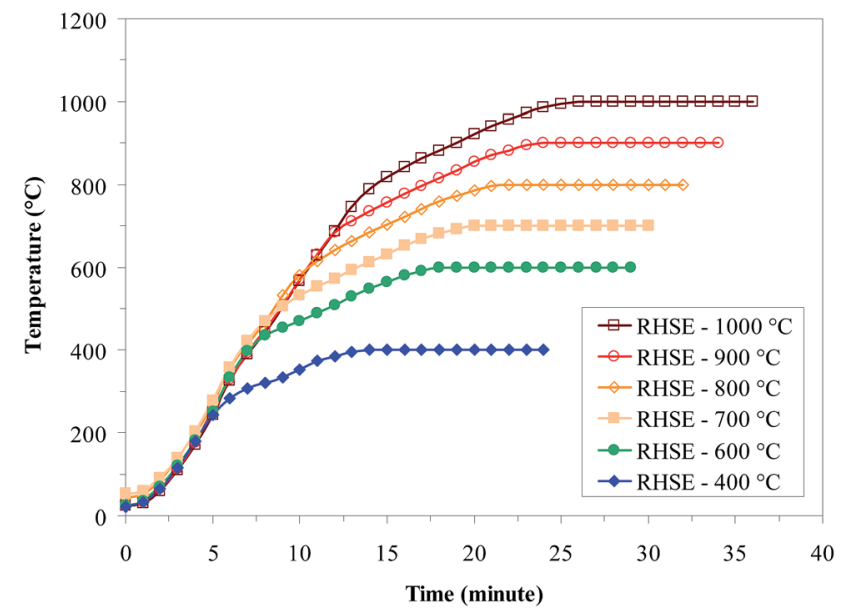

Fig. 2 Heating profile of the different calcination temperatures (RHSE: rapid heating short exposure - more details are given in an earlier publication ${ }^{28}$ ). 


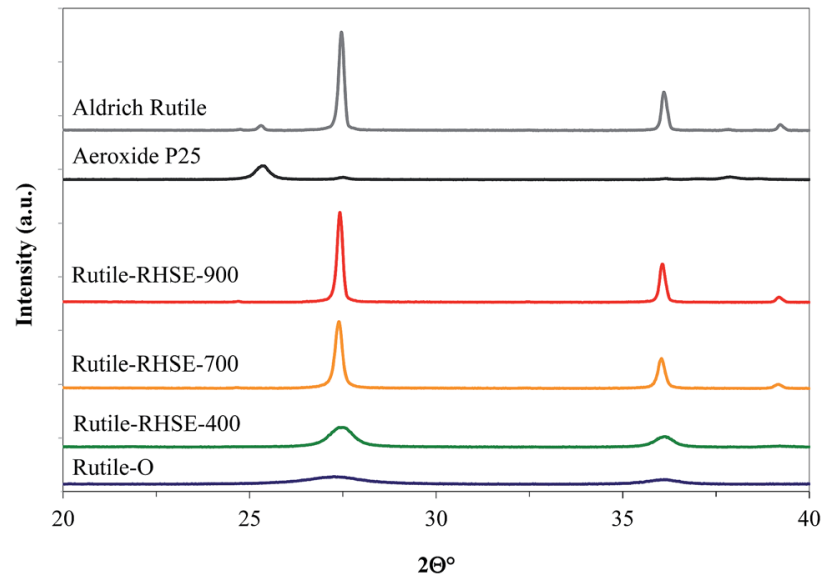

Fig. 3 XRD patterns of laboratory-made and commercial reference $\mathrm{TiO}_{2}$-S.

The laboratory-prepared rutile particles were mostly rounded, edgeless and polydisperse (e.g. Rutile-RHSE-900 contains particles with $D=100-400 \mathrm{~nm}$ ). The micrographs of Aldrich rutile and Rutile-RHSE-900 revealed very similar morphology and particle size distribution. Aeroxide P25 contained spherical and polyhedral (faceted) particles too.

The specific surface areas of the laboratory-made rutile titanias varied within a wide range $\left(1-197 \mathrm{~m}^{2} \mathrm{~g}^{-1}\right.$, Table 1). Noncalcined Rutile-O exhibited the highest value $\left(197 \mathrm{~m}^{2} \mathrm{~g}^{-1}\right)$, which decreased concomitantly with the temperature raising. It should be noted that Rutile-RHSE-900 and Aldrich rutile demonstrated the same specific surface area: $\sim 3 \mathrm{~m}^{2} \mathrm{~g}^{-1}$.

To investigate the light absorption properties of the synthesized photocatalysts, diffuse reflectance spectra were recorded (Fig. 5).

As the calcination temperature was increased, the light absorption of the produced rutile $\mathrm{TiO}_{2}$-s underwent a red shift (similar effect was demonstrated by Silva and Faria $^{29}$ ). Interestingly, Rutile-RHSE-900 and Rutile-RHSE-1000 displayed very similar light absorption properties to those of Aldrich rutile. Consequently, the increased visible light absorption of the $\mathrm{TiO}_{2}$-s calcined at higher temperatures is expected to be accompanied by higher photocatalytic activity under visible light irradiation.

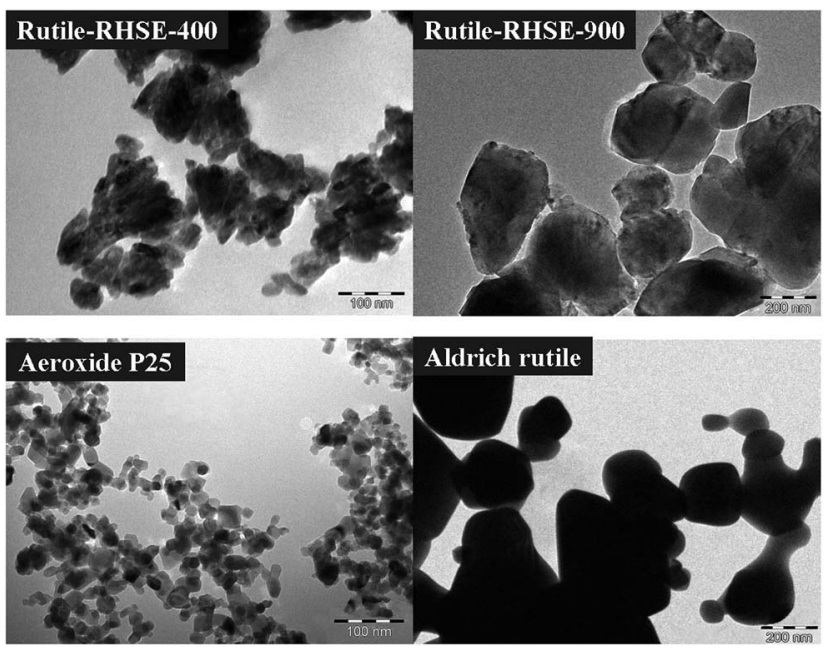

Fig. 4 TEM images of selected photocatalysts.

\subsection{Photocatalytic decomposition of phenol}

The phenol decay curves in Fig. 6 show that Aldrich rutile has high efficiency relative to the laboratory-made $\mathrm{TiO}_{2}$-s and Aeroxide P25. The initial degradation rates are listed in Table 1.

The photocatalytic experiments revealed the highest rate of phenol degradation for Rutile-O among the laboratory-made $\mathrm{TiO}_{2}$-s. Interestingly, the light absorption edge gradually shifted into the visible region (see Fig. 5) as the calcination temperature was increased. Furthermore, an increase in the primary particle size $(5-290 \mathrm{~nm})$ and a decrease in the specific surface area (from 197 to $1 \mathrm{~m}^{2} \mathrm{~g}^{-1}$ ) were also observed. A comparison of the photocatalytic activities with the abovementioned properties indicates the following important observations:

(i) the photocatalytic activity decreased slightly on elevation of the calcination temperature because of the lower specific surface area.

(ii) The surface-normalized rate of degradation of phenol ( $\left(\mathrm{mol} \mathrm{s}^{-1} \mathrm{~m}^{-2}\right.$ ) varied oppositely to the previous trend (Table 1). This could be due to the more efficient visible light absorption (see Fig. 5) of the $\mathrm{TiO}_{2}$-s calcined at higher temperatures.

Aldrich rutile has $\sim 22$ times higher photocatalytic efficiency than that of Rutile-RHSE-900, despite these $\mathrm{TiO}_{2}$-s having very

Table 1 Structural parameters of the investigated photocatalysts (crystal phase content, particle size and specific surface area), initial reaction rates determined for phenol decomposition under VIS irradiation, and initial reaction rates normalized to $1 \mathrm{~m}^{2}$ of surface

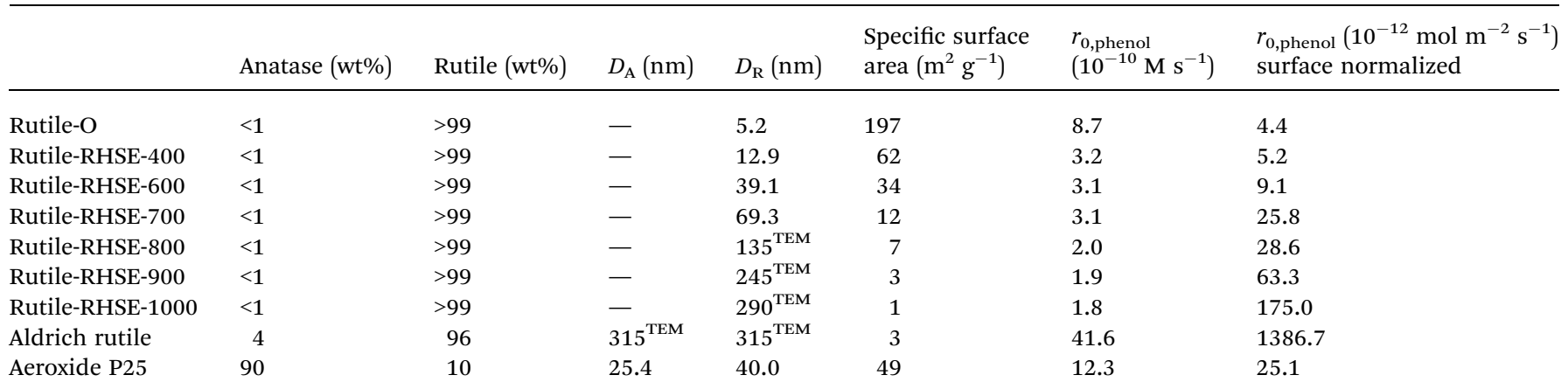




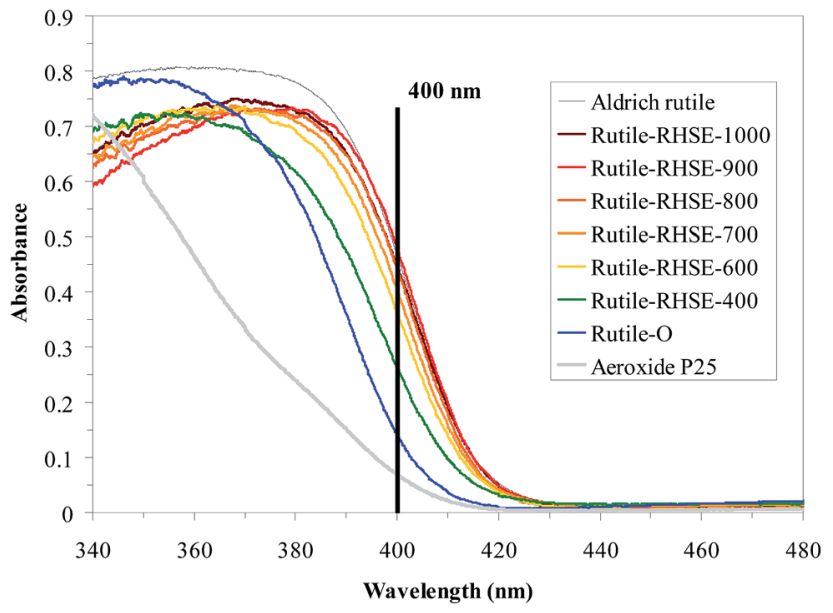

Fig. 5 DR spectra of investigated $\mathrm{TiO}_{2}-\mathrm{s}$.

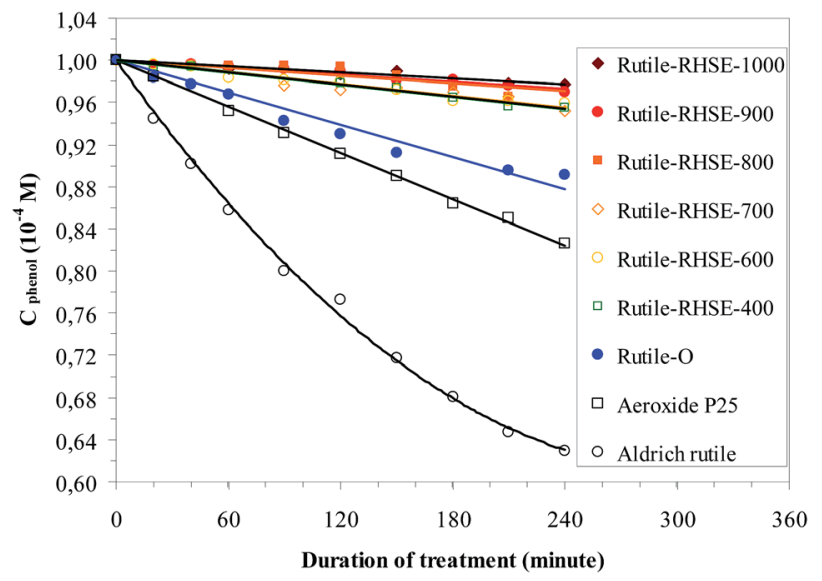

Fig. 6 Photocatalytic decomposition of phenol solutions.

similar specific surface area, particle size and morphology (rounded, edgeless shape, and highly polydispersed size distribution). The light absorption properties of these photocatalysts are also nearly the same.

The photocatalytic performances of the laboratory-made $\mathrm{TiO}_{2}$-s were compared with that of the most commonly used reference $\mathrm{TiO}_{2}$, Aeroxide P25. Rutile-O TiO 2 and Aeroxide P25 gave rise to similar phenol decomposition yields under visible light irradiation. The relatively high efficiency of Aeroxide P25 is very interesting, considering the fact that it contains mainly $(\sim 90 \%)$ anatase, which cannot be activated by visible light. There are some different explanations for this high efficiency in the literature. Balázs et $a l .{ }^{30}$ reported that polyhedral nanoparticles have higher photocatalytic activity than spherical ones, and Aeroxide P25 contains polyhedral particles whereas Aldrich rutile and the laboratory-made photocatalysts do not (see Fig. 4). Another explanation is provided by Rajashekhar and Devi $^{31}$ and by Ohno et al.: $:^{32}$ they describe a special synergetic effect of anatase and rutile nanoparticles in Aeroxide P25, which can result in the high activity of this type of $\mathrm{TiO}_{2}$. However this synergetic effect is doubted by Ohtani $e t a l .^{33}$

\subsection{Photocatalytic disinfection of $E$. coli-contaminated water}

For the visible light irradiation of $\mathrm{TiO}_{2}$ and E. coli-containing suspensions $(50 \mu \mathrm{L})$ were plated on agar gels and the grown colonies were counted after a $24 \mathrm{~h}$ incubation at $37^{\circ} \mathrm{C}$ in the dark. The results of these disinfection experiments are summarized in Fig. 7. All of the experiments were repeated twice, and the averages are presented.

The grown colonies are illustrated in a photo (see Fig. 8) in the case of Rutile-O. More than $90 \%$ of the E. coli cells were killed after $2 \mathrm{~h}$ of irradiation in the presence of this $\mathrm{TiO}_{2}$ with its very small nanoparticles $(\sim 5 \mathrm{~nm})$.

None of the other (calcined) laboratory-made rutile photocatalysts exhibited any disinfection properties after the 120 min irradiation. Aeroxide P25 totally sterilized the water after 60 min, while Aldrich rutile (with large nanoparticles $\sim 315$ $\mathrm{nm}$ ) did so after 20 min whereas Rutile-RHSE-900 (with a similar particle size and the same specific surface area as those of Aldrich rutile) was not active at all. In experiments with the $\mathrm{TiO}_{2}$-s without irradiation, no antibacterial effect was seen.

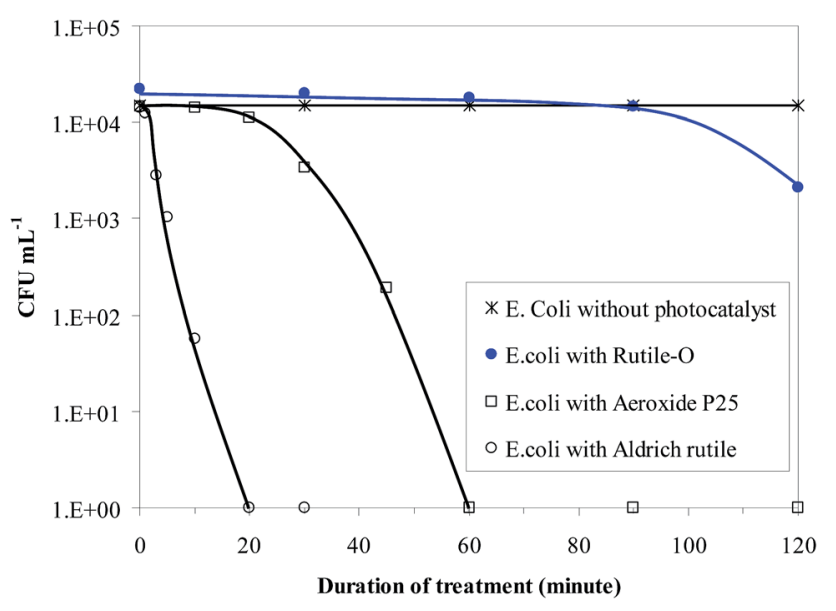

Fig. 7 Photocatalytic E. coli disinfection experiments.

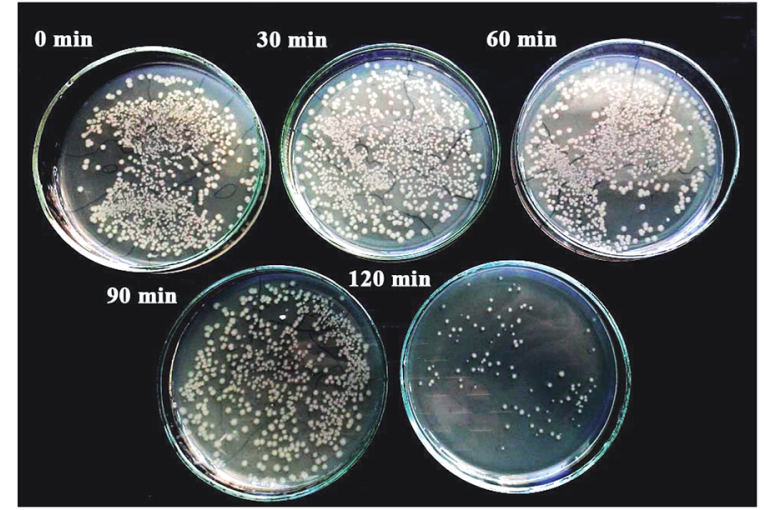

Fig. 8 E. coli colonies grown in photocatalytic disinfection experiment with laboratory-made Rutile- $O$. 


\subsection{Discussion}

Aldrich rutile with large particle size $(\sim 315 \mathrm{~nm})$ showed the highest disinfection performance. Unfortunately, the rutile with the smallest particle size (among the obtained rutile samples) exhibited a significantly lower disinfection performance. Moreover the larger rutiles did not show any disinfection property. This means that the particle size of rutile is not a crucial factor in visible light induced photocatalytic disinfection. Furthermore, Aldrich rutile and self-made Rutile-RHSE-
$900 \mathrm{TiO}_{2}$ with similar structural properties (specific surface area, particle size, shape and size distribution) demonstrated very different photocatalytic activities. Accordingly a close correlation was not observed between these structural parameters and the photocatalytic efficiency of rutile-phase titanium dioxides.

In an attempt to explain the great difference in photocatalytic efficiency, X-ray photoelectron, and IR spectroscopic and EPR examinations were also carried out on these two samples.
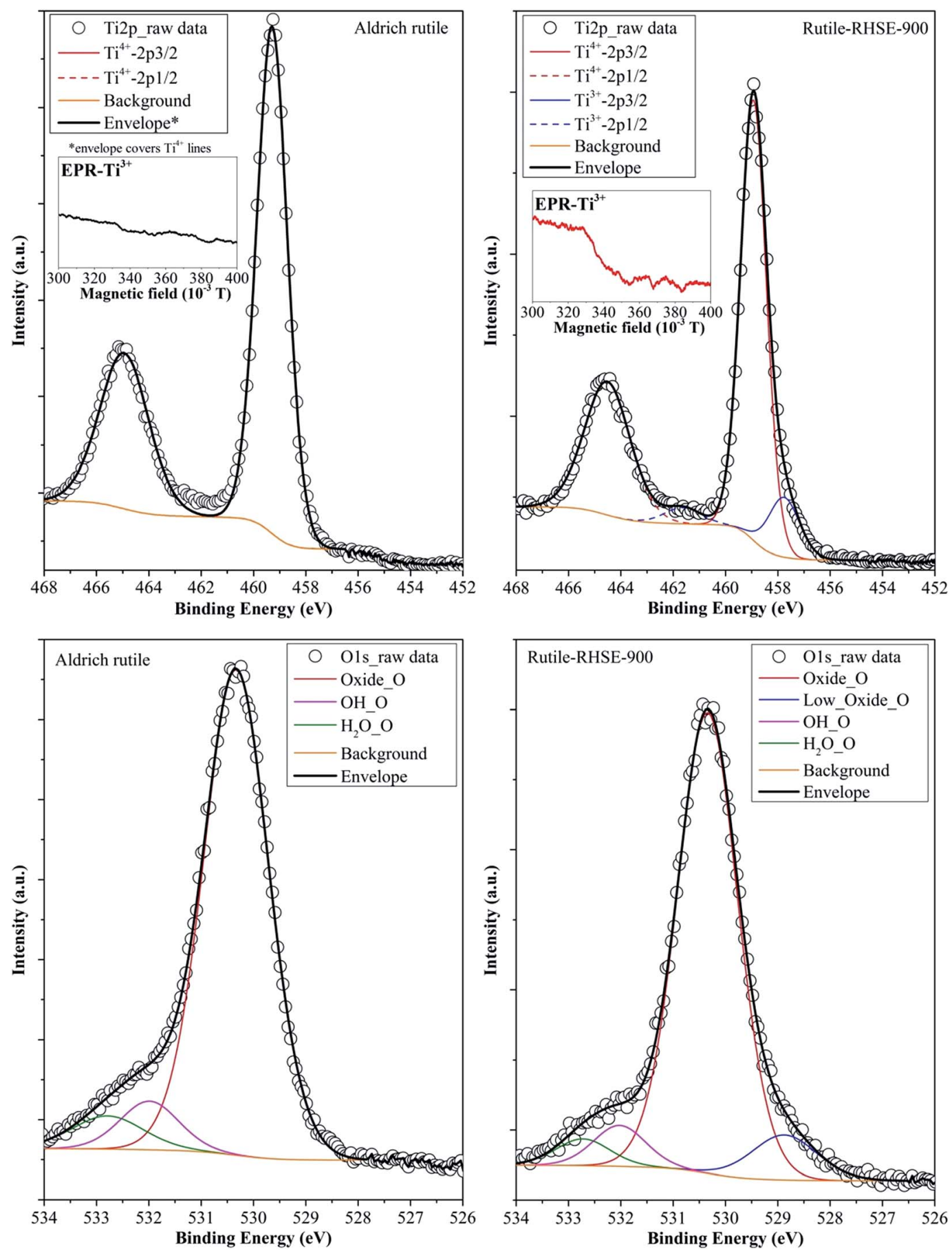

Fig. 9 Ti 2p and O 1s XP spectra of Aldrich rutile and Rutile-RHSE-900. 
X-ray photoelectron spectra ( $\mathrm{Ti} 2 \mathrm{p}, \mathrm{O} 1 \mathrm{~s})$ are presented in Fig. 9.

The surface of the Aldrich rutile does not appear unusual. In the Ti 2 p XPS spectrum only $\mathrm{Ti}^{4+}$ was detected, while the $\mathrm{O} 1 \mathrm{~s}$ spectrum revealed the usual components: oxide oxygen from $\mathrm{TiO}_{2}(530.3 \mathrm{eV})$, surface $\mathrm{OH}$ group oxygen (532 eV), and oxygen from $\mathrm{H}_{2} \mathrm{O}(532.8 \mathrm{eV})$. As the Rutile-RHSE-900 was made by the rapid heat treatment method, ${ }^{27,28,34}$ we expected the appearance of new spectral features. Indeed, in the Ti 2p XPS spectrum a small amount of $\mathrm{Ti}^{3+}$ was observed (13 at\%: peaks at $457.3 \mathrm{eV}$ and $461.9 \mathrm{eV})$, along with $\mathrm{Ti}^{4+}(87$ at\%: peaks at $459.1 \mathrm{eV}$ and $464.8 \mathrm{eV}) .{ }^{27}$ The $\mathrm{O} 1 \mathrm{~s}$ spectrum of this material indicated a low binding energy oxygen species (at $528.8 \mathrm{eV}, 12$ at\%). On the basis of recent publications, ${ }^{27,28}$ this interesting form of oxygen was ascribed to the presence of oxygen defects, or to oxygen atoms adjacent to reduced $\mathrm{Ti}$ sites $\left(\right.$ i.e. $\left.\mathrm{Ti}^{3+}\right)$. This is reinforced by the fact that $\mathrm{Ti}^{3+}$ and the low binding energy oxygen are interdependent entities: if one them appears in a surface composition, so does the other. In the cases of the other fast heat-treated $\mathrm{TiO}_{2}$-s (in which the predominant crystal phase was anatase), the presence of this special species was earlier observed to enhance the photocatalytic activity (UV - phenol degradation) as it is described in our previous study. ${ }^{27}$ In the present study (rutile - VIS - phenol degradation), the presence of this species did not enhance the photocatalytic performance: a drastic inhibition was registered. Consequently the specific roles of $\mathrm{Ti}^{3+}$ and $\mathrm{O}$ vacancies needs further investigations as it is also emphasized by $\mathrm{Su}$ et al. in their excellent review article ${ }^{35}$ about the complexity of this topic.

To get further evidence, EPR measurements were carried out, which proved the presence of $\mathrm{Ti}^{3+}$ in Rutile-RHSE-900 (ref. 36 and 37) (see the inset of Fig. 9). As it can be seen, until now, there are no clear evidences concerning the higher photocatalytic activity. The explanation regarding this issue, must be surface related, as the photocatalytic properties are surface quality dependent phenomena.

Hence, IR measurements were carried out and were presented in Fig. 10. The usual features were noted for both samples, the most important being the broad band centered at

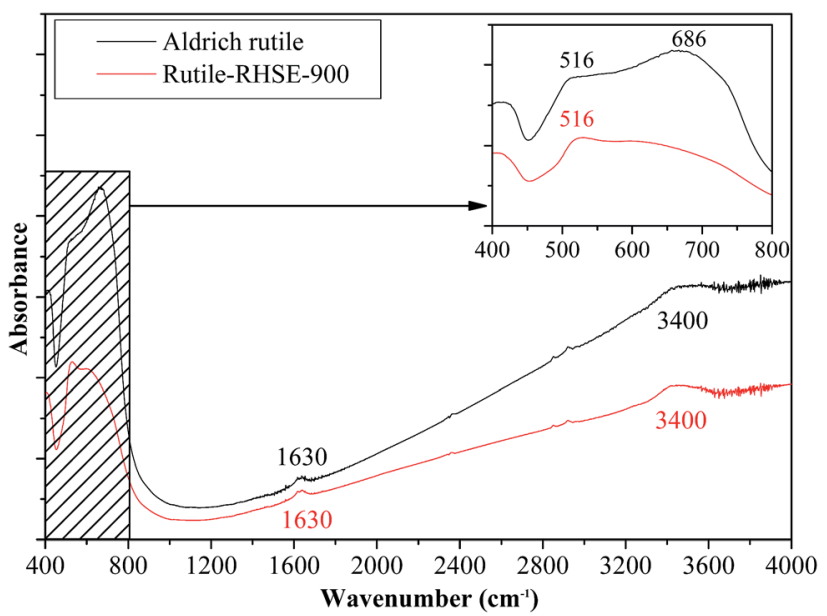

Fig. 10 IR spectra of Aldrich rutile and Rutile-RHSE-900 samples.
$3400 \mathrm{~cm}^{-1}$, with a sharp band at $1630 \mathrm{~cm}^{-1}$, which can be attributed to the stretching and bending vibrations of the surface $\mathrm{OH}$ group. ${ }^{27}$

In the inset of Fig. 10, the Ti-O-Ti bond stretching vibrations can be identified at $519 \mathrm{~cm}^{-1}$ for the rutile phase. ${ }^{38}$ The samples presented similar peaks of $\mathrm{CO}_{2}$ at $2380 \mathrm{~cm}^{-1}$. The only difference between the IR spectra is the appearance of a new band for Aldrich rutile at $687 \mathrm{~cm}^{-1}$, which corresponds to Ti-O-O- bond stretching vibrations. ${ }^{\mathbf{8}, 39-41}$ This indicates an oxygen-rich surface on the catalyst, which could be an electrophilic entity. Since rutile is activated in visible light (as shown by the DRS spectra) and the charge carriers are formed as usual, this "peroxidized" surface can attract electrons, which can then be easily captured by molecular oxygen, resulting finally in higher radical generation (high hydroxyl radical generation was proved in our earlier publication ${ }^{\mathbf{1 4}}$ in case of visible light activated Aldrich rutile). Shankar and coworkers, ${ }^{40}$ and Zou and co-workers ${ }^{41}$ also reported enhanced photocatalytic activity in their $\mathrm{Ti}-\mathrm{O}-\mathrm{O}-$ groups containing, laboratory prepared titanium-dioxides.

\section{Conclusions}

A method for the synthesis of nanosized $(\sim 5 \mathrm{~nm})$, pure rutilephase, non-doped $\mathrm{TiO}_{2}$ was developed (Rutile-O), by the hydrolysis of $\mathrm{Ti}(\mathrm{O}-n \mathrm{Bu})_{4}$ in $\mathrm{HCl}$ solution, and crystallization in a water bath at low temperature $\left(40^{\circ} \mathrm{C}\right)$. A series of rutile with increasing particle size $(12.9,39.1,69.3,135,245$ and $290 \mathrm{~nm})$ were produced by the calcination of Rutile-O at different temperatures $\left(400-1000{ }^{\circ} \mathrm{C}\right)$.

The DR spectra indicated that the light absorption was shifted into the visible region on increase of the calcination temperature, which may explain the significantly increased surface-normalized photocatalytic performance of the calcined $\mathrm{TiO}_{2}$-s.

The results of XRD, DRS, BET and TEM characterization methods demonstrated that Aldrich rutile and the laboratorymade Rutile-RHSE-900 have very similar properties, such as particle size, specific surface area, morphology and light absorption, but they differ significantly in photocatalytic efficiency (for either phenol decomposition or disinfection). A close correlation was not observed between these structural parameters and the photocatalytic efficiency of rutile.

The present work highlighted that surface properties causes much higher differences in photocatalytic performances than specific surface area, and the importance of the presence of $\mathrm{Ti}^{3+}$ was re-evaluated. It emerged from XPS and EPR measurements that the presence of $\mathrm{Ti}^{3+}$ and low-binding-energy oxygen on rutile does not enhance the photocatalytic performance (under visible light irradiation). However, the IR measurements revealed that Aldrich rutile has an oxygen-rich surface ( $\mathrm{Ti}-\mathrm{O}-\mathrm{O}-$ entities), which can result in higher radical generation efficiency (despite it's low specific surface area: $\sim 3 \mathrm{~m}^{2} \mathrm{~g}^{-1}$ ). The presented results pointed out that the presence of $\mathrm{Ti}-\mathrm{O}-\mathrm{O}-$ entities is more preferable than the presence of $\mathrm{Ti}^{3+}$ in relation with the photocatalytic performance of rutile under visible light irradiation. Based on these results a next challenge is to prepare 
rutile-phased titanium dioxide with high specific surface area, containing $\mathrm{Ti}-\mathrm{O}-\mathrm{O}-$ groups on the surface.

\section{Acknowledgements}

This research was supported by the European Union and the State of Hungary, co-financed by the European Social Fund in the framework of TÁMOP 4.2.4. A/2-11-1-2012-0001 'National Excellence Program'. This work was partially co-financed by the Swiss Contribution (SH/7/2/20). This work was supported for the Romanian authors by a grant of the Romanian National Authority for Scientific Research, CNCS-UEFISCDI, project number PN-II-ID-PCE-2011-3-0442. KM is grateful for the financial support of the János Bolyai Research Scholarship of the Hungarian Academy of Sciences. The authors are indebted to Evonik Industries for supporting our work by supplying $\mathrm{TiO}_{2}$ $\mathrm{s}$ for these studies. The authors are grateful for the research group of László Manczinger (Department of Microbiology; University of Szeged) for the helpful contribution in microbial experiments.

\section{Notes and references}

1 R. Zha, R. Nadimicherla and X. Guo, RSC Adv., 2015, 5, 64816488.

2 M. Li, S. Zhang, Y. Peng, L. Lv and B. Pan, RSC Adv., 2014, 5, 7363-7369.

3 W. Sun, H. Liu, J. Hu and J. Li, RSC Adv., 2015, 5, 513-520.

4 M. Abbasnejad, E. Shojaee, M. R. Mohammadizadeh, M. Alaei and R. Maezono, Appl. Phys. Lett., 2012, 100, 261902.

5 Y. Wang, H. Zhang, P. Liu, X. Yao and H. Zhao, RSC Adv., 2013, 3, 8777 .

6 J. Orlikowski, B. Tryba, J. Ziebro, A. W. Morawski and J. Przepiórski, Catal. Commun., 2012, 24, 5-10.

7 M. A. Fox and M. T. Dulay, Chem. Rev., 1993, 93, 341-357.

8 V. Etacheri, M. K. Seery, S. J. Hinder and S. C. Pillai, Adv. Funct. Mater., 2011, 21, 3744-3752.

9 S. Banerjee, J. Gopal, P. Muraleedharan, A. Tyagi and B. Rai, Curr. Sci., 2005, 90, 1378-1383.

10 S. Yin, H. Hasegawa, D. Maeda, M. Ishitsuka and T. Sato, J. Photochem. Photobiol., A, 2004, 163, 1-8.

11 K.-C. Huang and S.-H. Chien, Appl. Catal., B, 2013, 140-141, 283-288.

12 H. Nagai, S. Aoyama, H. Hara, C. Mochizuki, I. Takano, N. Baba and M. Sato, J. Mater. Sci., 2008, 44, 861-868.

13 V. Caratto, B. Aliakbarian, A. A. Casazza, L. Setti, C. Bernini, P. Perego and M. Ferretti, Mater. Res. Bull., 2013, 48, 20952101.

14 G. Veréb, L. Manczinger, G. Bozsó, A. Sienkiewicz, L. Forró, K. Mogyorósi, K. Hernádi and A. Dombi, Appl. Catal., B, 2013, 129, 566-574.

15 F. Amano and M. Nakata, Appl. Catal., B, 2014, 158-159, 202208.
16 G. Veréb, Z. Ambrus, Z. Pap, Á. Kmetykó, A. Dombi, V. Danciu, A. Cheesman and K. Mogyorósi, Appl. Catal., A, 2012, 417-418, 26-36.

17 Z. Tang, J. Zhang, Z. Cheng and Z. Zhang, Mater. Chem. Phys., 2002, 77, 314-317.

18 P. Wu, R. Xie, J. A. Imlay and J. K. Shang, Appl. Catal., B, 2009, 88, 576-581.

19 J. A. Rengifo-Herrera, J. Kiwi and C. Pulgarin, J. Photochem. Photobiol., A, 2009, 205, 109-115.

20 P. Wu, J. A. Imlay and J. K. Shang, Biomaterials, 2010, 31, 7526-7533.

21 J. A. Rengifo-Herrera, K. Pierzchała, A. Sienkiewicz, L. Forró, J. Kiwi and C. Pulgarin, Appl. Catal., B, 2009, 88, 398-406.

22 H. U. Lee, S. C. Lee, S. Choi, B. Son, S. M. Lee, H. J. Kim and J. Lee, Chem. Eng. J., 2013, 228, 756-764.

23 D. Dolat, S. Mozia, B. Ohtani and A. W. Morawski, Chem. Eng. J., 2013, 225, 358-364.

24 M. Gopal, W. J. M. Chan and L. C. DeJonghe, J. Mater. Sci., 1997, 32, 6001-6008.

25 Q. P. Wu and R. van de Krol, J. Am. Chem. Soc., 2012, 134, 9369-9375.

26 M. Y. Xing, J. L. Zhang, F. Chen and B. Z. Tian, Chem. Commun., 2011, 47, 4947-4949.

27 Z. Pap, É. Karácsonyi, Z. Cegléd, A. Dombi, V. Danciu, I. C. Popescu, L. Baia, A. Oszkó and K. Mogyorósi, Appl. Catal., B, 2012, 111, 595-604.

28 Z. Pap, V. Danciu, Z. Cegléd, Á. Kukovecz, A. Oszkó, A. Dombi and K. Mogyorósi, Appl. Catal., B, 2011, 101, 461-470.

29 C. G. Silva and J. L. Faria, Photochem. Photobiol. Sci., 2009, 8, 705.

30 N. Balázs, K. Mogyorósi, D. F. Srankó, A. Pallagi, T. Alapi, A. Oszkó, A. Dombi and P. Sipos, Appl. Catal., B, 2008, 84, 356-362.

31 K. E. Rajashekhar and L. G. Devi, J. Mol. Catal. A: Chem., 2013, 374, 12-21.

32 T. Ohno, K. Sarukawa and M. Matsumura, J. Phys. Chem. B, 2001, 105, 2417-2420.

33 B. Ohtani, O. O. Prieto-Mahaney, D. Li and R. Abe, J. Photochem. Photobiol., A, 2010, 216, 179-182.

34 K. Mogyorósi, É. Karácsonyi, Z. Cegléd, A. Dombi, V. Danciu, L. Baia and Z. Pap, J. Sol-Gel Sci. Technol., 2013, 65, 277-282.

35 J. Su, X. Zou and J.-S. Chen, RSC Adv., 2014, 4, 13979.

36 R. F. Howe and M. Grätzel, J. Phys. Chem., 1985, 89, 44954499.

37 V. M. Khomenko, K. Langer, H. Rager and A. Fett, Phys. Chem. Miner., 1998, 25, 338-346.

38 T. Busani and R. A. B. Devine, Semicond. Sci. Technol., 2005, 20, 870-875.

39 M. R. Ayers and A. J. Hunt, Mater. Lett., 1998, 34, 290-293.

40 M. V. Shankar, T. Kako, D. Wang and J. Ye, J. Colloid Interface Sci., 2009, 331, 132-137.

41 J. Zou, J. Gao and F. Xie, J. Alloys Compd., 2010, 497, 420-427. 